\title{
Application of NMR-based metabonomics suggests a relationship between betaine absorption and elevated creatine plasma concentrations in catheterised sows
}

\author{
Christian Clement Yde ${ }^{1,2 *}$, Johan A. Westerhuis ${ }^{3}$, Hanne Christine Bertram ${ }^{2}$ and \\ Knud Erik Bach Knudsen ${ }^{1}$ \\ ${ }^{1}$ Department of Animal Science, Faculty of Science and Technology, Aarbus University, 8830 Tjele, Denmark \\ ${ }^{2}$ Department of Food Science, Faculty of Science and Technology, Aarbus University, 5792 Aarslev, Denmark \\ ${ }^{3}$ Biosystems Data Analysis, Faculty of Sciences, University of Amsterdam, $1018 \mathrm{WV}$ Amsterdam, The Netherlands \\ (Submitted 25 November 2010 - Final revision received 1 August 2011 - Accepted 3 August 2011 - First published online 28 September 2011)
}

\section{Abstract}

The objective of the present explorative study was to determine the absorption dynamics when feeding diets varying in types and levels of dietary fibre in a catheterised animal model. A total of six sows were fed a diet low in fibre (LF), a diet high in soluble fibre and a diet high in insoluble fibre in a repeated $3 \times 3$ cross-over design. Plasma samples were collected from the mesenteric artery and the portal vein to determine different absorption phases by ${ }^{1} \mathrm{H}$ NMR spectroscopy-based metabonomics. Time profiles were determined for plasma levels of specific metabolites and for the absorption of these metabolites from the small intestine. The LF diet resulted in a higher betaine concentration in the blood than the two high-fibre diets $(P=0 \cdot 008)$. This leads to higher plasma concentrations of methionine $(P=0 \cdot 0028)$ and creatine $(P=0.020)$ of endogenous origin. In conclusion, the use of NMR spectroscopy for measuring nutrient uptake in the present study elucidated the relationship between betaine uptake and elevated creatine plasma concentrations.

Key words: Absorption: Betaine: Dietary fibre: Metabonomics: NMR spectroscopy

The dietary fibre (DF) fraction represents a very diverse group of polysaccharides organised as a three-dimensional network that makes up the major part of plant cell walls ${ }^{(1)}$. While the DF level of conventional feeds for sows typically varies between 150 and $250 \mathrm{~g} / \mathrm{kg}$ DM, very high DF diets (400$500 \mathrm{~g} / \mathrm{kg}$ DM) may be applied for pregnant sows to prolong the feeling of satiety and reduce the stereotypic behaviour of loose reared pregnant sows ${ }^{(2,3)}$. DF has also shown numerous health benefits in human studies; for example, evidence has been obtained that DF reduces risk factors for CHD such as hyperlipidaemia ${ }^{(4,5)}$, a high intake of soluble DF improves glycaemic control in type 2 diabetes $^{(6)}$ and improves gastrointestinal health ${ }^{(7)}$. Consequently, both from an animal and human nutrition point of view, obtaining a better understanding of the metabolic consequences of DF consumption is of interest.

Metabonomics is an emerging tool in nutritional physiology ${ }^{(8,9)}$. It is referred to as the quantitative measurement of the dynamic multiparametric metabolic response of living systems to pathophysiological stimuli or genetic modification $^{(10)}$. This can be seen as metabolic profiles of the metabolic network measured in tissue or more typically in biofluids. Accordingly, metabonomics in combination with classical animal models, e.g. the catheterised pig model, can provide new insight into the absorption and metabolism of nutrients. The catheterised pig model with permanent catheters placed in the portal vein and the mesenteric artery and a flow probe around the portal vein is a well-established model for studying the uptake of water-soluble compounds to the portal vein system ${ }^{(11,12)}$.

NMR spectroscopy is a commonly used tool for metabonomics and has been used to study the metabolic response in toxicology and pharmacology ${ }^{(10,13-15)}$ but also to identify specific components in nutritional studies ${ }^{(16-22)}$. NMR is an inherently quantitative and non-destructive technique that requires little or no sample preparation. In principle, liquidstate ${ }^{1} \mathrm{H}$ NMR spectroscopy detects all mobile proton-containing metabolites. Thus, ${ }^{1} \mathrm{H}$ NMR spectroscopy is a powerful tool for holistic and explorative investigations. The measurements, however, suffer from low sensitivity compared with other

Abbreviations: $\triangle \mathrm{AV}$, arterial-venous difference; CMV, cross-model validation; DF, dietary fibre; HFI, high-fibre insoluble diet; HFS, high-soluble fibre; LF, low fibre; MLPLSDA, multilevel partial least-squares discriminant analysis; PPM, parts per million; RP, rank product.

*Corresponding author: Dr C. C. Yde, email christianc.yde@agrsci.dk 
methods, e.g. MS. In a recent study, we investigated the quantitative uptake of glucose, lactate and SCFA and the apparent insulin production in sows fed a concentrated control diet and two high-fibre diets (approximately $440 \mathrm{~g}$ $\mathrm{DF} / \mathrm{kg} \mathrm{DM}$ ) composed of co-products from the vegetable food and agro industries by using traditional analytical methods ${ }^{(23,24)}$. The results from ${ }^{1} \mathrm{H}$ NMR spectroscopy of blood samples from the present study have been presented in a short paper ${ }^{(25)}$ that indicated a relationship between betaine uptake and elevated creatine plasma concentrations. In the present study, we further expanded the previous findings to provide a more complete insight into the metabolites that are altered as a result of DF ingestion and the dynamic aspect of absorption. Consequently, the main objective of the present study was to investigate whether ${ }^{1} \mathrm{H}$ NMR-based metabonomics can provide new and a more complete insight into nutritive and non-nutritive components released during the digestion processes and the metabolism thereof. For this purpose, we used plasma samples from the mesenteric artery and the portal vein of six catheterised sows. The principle of the method that has been used in the present study is as follows: (1) blood samples that have been simultaneously collected from the mesenteric artery and the portal vein; (2) establishment of ${ }^{1} \mathrm{H}$ NMR arterial-venous differences $(\Delta \mathrm{AV})$; (3) identification of biomarkers by a multivariate approach using the multilevel structured cross-over study design; (4) use of biomarkers in an ANOVA model for time profiles and determination of significant variation.

\section{Materials and methods}

\section{Diets}

For the purpose of the study, three diets were prepared from whole wheat and barley supplemented with different co-products from the vegetable food and agro industries: potato pulp, KMC (Brande, Denmark); sugarbeet pulp, Danisco Sugar A/S (Assens, Denmark); pectin residue, CPKelco ApS (Lille Skensved, Denmark); brewers' spent grain, Agro-korn A/S (Videbæk, Denmark); pea hulls and seed residue, DLF Trifolium A/S (Roskilde, Denmark). The diets were formulated to contain different types and levels of DF (see Table 1 for composition). A low-DF diet (LF; $177 \mathrm{~g} \mathrm{DF} / \mathrm{kg}$ DM) was prepared from wheat and barley as the main carbohydrate source and two high-DF diets (approximately $440 \mathrm{~g}$ DF/kg DM) were prepared by substituting wheat and barley with sugarbeet pulp, potato pulp and pectin residue (high-soluble fibre, HFS) and with approximately one-third of sugarbeet pulp, potato pulp and pectin residue and twothirds of brewers' spent grain, pea hulls and seed residue (high-fibre insoluble diet, HFI). The diets were formulated to meet the Danish recommendations for essential macro- and micronutrients and were milled to pass through a $2 \mathrm{~mm}$ screen. The daily feeding level was $2000 \mathrm{~g}$ feed (as-fed basis) once per $\mathrm{d}$ and the sows had free access to water. In our diet formulation, proper adjustment was made to ensure a sufficient and similar supply of digestible amino acids in all three diets, which was the reason for the greater
Table 1. Dietary ingredients ( $\mathrm{g} / \mathrm{kg}$ diet) of the experimental diets

\begin{tabular}{lccr}
\hline Diets & LF & HFS & HFI \\
\hline Barley & 420 & 145 & 145 \\
Wheat & 420 & 145 & 145 \\
Sugarbeet pulp & - & 140 & 50 \\
Pectin residue & - & 140 & 50 \\
Potato pulp & - & 140 & 50 \\
Seed residue & - & - & 135 \\
Pea hulls & - & - & 135 \\
Brewers' spent grain & - & - & 135 \\
Soya oil & 50 & 50 & 50 \\
Soyabean meal, toasted & 75 & 216 & 84 \\
Marker (chromic oxide) & 2 & 2 & 2 \\
Monocalcium phosphate & 22 & 11 & 11 \\
Calcium carbonate & 6 & 6 & 3 \\
NaCl & 3 & 3 & 2 \\
Vitamin/mineral mix & 2 & 2 &
\end{tabular}

LF, low-fibre diet; HFS, high-fibre soluble diet; HFI, high-fibre insoluble diet.

* Provided per $\mathrm{kg}$ of final diet: $3.03 \mathrm{mg}$ retinol acetate; $25 \mu \mathrm{g}$ cholecalciferol; $60 \mathrm{mg}$ all rac DL- $\alpha$-tocopherol acetate; $2.2 \mathrm{mg}$ menadione; $2.2 \mathrm{mg}$ thiamin; $5.5 \mathrm{mg}$ riboflavin; $3.3 \mathrm{mg}$ pyridoxine; $16.5 \mathrm{mg}$ D-pantothenic acid; $22 \mathrm{mg}$ niacin; $1.65 \mathrm{mg}$ folic acid; $220 \mu \mathrm{g}$ biotin; $22 \mu \mathrm{g}$ cyanocobalamin; $60 \mathrm{mg}$ butylated hydroxytoluene $100 \mathrm{mg} \mathrm{Fe}$ as $\mathrm{FeSO}_{4} \cdot 7 \mathrm{H}_{2} \mathrm{O} ; 150 \mathrm{mg} \mathrm{Zn}$ as $\mathrm{ZnO} ; 28 \mathrm{mg} \mathrm{Mn}$ as $\mathrm{MnO} ; 20 \mathrm{mg} \mathrm{Cu}$ as $\mathrm{CuSO}_{4} \cdot 5 \mathrm{H}_{2} \mathrm{O} ; 304 \mu \mathrm{g} \mathrm{I}$ as $\mathrm{KI} ; 300 \mu \mathrm{g}$ Se as $\mathrm{Na}_{2} \mathrm{SeO}_{3}$.

total protein concentration of the two high-DF diets compared with the LF diet (Table 2). The amount of carbohydrates was greatest in the LF diet $(698 \mathrm{~g} / \mathrm{kg} \mathrm{DM})$ and similar in the HFS and HFI diets (628-622 g/kg DM). The LF diet had the greatest starch content, whereas it was much less in the two high-DF diets. The two high-DF diets were similar in total NSP and similar in cellulose and non-cellulosic polysaccharides but with variable proportions of water-soluble-to-insoluble non-cellulosic polysaccharides (30:70 in the HFS diet and 20:80 in the HFI diet). The different chemical compositions translate into differences in the physico-chemical properties of the diets. Swelling and water-binding capacity were greatest in the HFS diet and least in the LF diet. The daily intake of

Table 2. Chemical composition and physico-chemical properties of the experimental diets

\begin{tabular}{lrrr}
\hline Diets & LF & HFS & HFI \\
\hline Chemical composition (g/kg DM) & & & \\
Ash & 57 & 65 & 76 \\
Protein (N $\times 6 \cdot 25)$ & 138 & 178 & 170 \\
Fat & 84 & 86 & 94 \\
Total carbohydrates & 698 & 628 & 622 \\
Sugars & 19 & 36 & 24 \\
Fructan & 9 & 7 & 6 \\
Starch & 517 & 216 & 225 \\
Total NSP & 144 & 369 & 367 \\
$\quad$ Soluble NSP & 44 & 111 & 74 \\
Cellulose & 32 & 151 & 160 \\
Non-cellulosic polysaccharides & 112 & 218 & 207 \\
$\quad$ Soluble NSP & 44 & 111 & 74 \\
Klason lignin & 33 & 60 & 88 \\
Dietary fibre (lignin + NSP) & 177 & 429 & 455 \\
$\quad$ Soluble NSP & 44 & 111 & 74 \\
Physico-chemical properties (units/kg DM) & & & \\
Swelling (litres) & 4.13 & 6.43 & 5.44 \\
Water-binding capacity (kg) & 1.34 & 3.14 & 2.58 \\
\hline
\end{tabular}

LF, low-fibre diet; HFS, high-fibre soluble diet; HFI, high-fibre insoluble diet. 
metabolisable energy was $24.9 \mathrm{MJ}$ for the LF diet, $24.0 \mathrm{MJ}$ for the HFS diet and $20.7 \mathrm{MJ}$ for the HFI diet (data obtained from Serena et al. ${ }^{(26)}$ ). The intake of metabolisable energy was significantly lower for the HFI diet than for the two other diets.

\section{Animals}

Experiments complied with the guidelines of the Danish Animal Experiments Inspectorate, Ministry of Justice, Copenhagen, Denmark, with respect to animal experimentation and care of the animals under study. The experiment was carried out as a $3 \times 3$ repeated cross-over design with six sows fed the three different diets: LF, HFS and HFI, $7 \mathrm{~d}$ /diet. Non-pregnant sows with an initial average body weight of 202 (SD 28) kg were selected after weaning of their first litter (Peter Bøjlesen, Vammen, Denmark). After $10 \mathrm{~d}$ of adaptation, each sow was surgically fitted with two catheters, one in the portal vein $(1.2 \mathrm{~mm}$ in inner diameter and $2.3 \mathrm{~mm}$ in outer diameter; Cole-Parmer, Vernon Hills, IL, USA) and the other in the mesenteric artery $(1.0 \mathrm{~mm}$ in inner diameter and $1.8 \mathrm{~mm}$ in outer diameter; Cole-Parmer), and with an ultrasonic blood flow probe (28A probe, $28 \mathrm{~mm}$; Transonic System, Inc., Ithaca, NY, USA) around the portal vein. A flowmeter (Transonic T206 flowmeter with P-option; Transonic System, Inc.) was used for measuring the blood flow rate. After a $7 \mathrm{~d}$ recovery period from the surgery, the sows were introduced to one of the three experimental diets. Sows were placed in farrowing pens during the collection of blood from the portal vein and the mesenteric artery. Blood samples were collected the last day in each treatment period at $0,1,4$ and $10 \mathrm{~h}$ after feeding. The blood was collected into heparinised plastic tubes and centrifuged (1800 $\boldsymbol{g}$ in $10 \mathrm{~min}$ at $8^{\circ} \mathrm{C}$ ). Plasma was frozen until further analysis. On the days of blood sampling, any feed leftovers were collected. For further details on the experimental protocol, see Serena et al. ${ }^{(24)}$.

\section{${ }^{1} \mathrm{H} N \mathrm{~N}$ R spectroscopic analysis}

All NMR spectra were recorded on a Bruker $600 \mathrm{MHz}$ NMR spectrometer (Bruker Biospins, Rheinstetten, Germany) operating at a frequency of $600 \cdot 13 \mathrm{MHz}$ for ${ }^{1} \mathrm{H}$ and equipped with a $5 \mathrm{~mm}$ TXI (triple resonance inverse) probe. Then, $200 \mu \mathrm{l}$ aliquots of the plasma samples were mixed with a solution of $400 \mu \mathrm{l}$ of $0.9 \%$ saline $(\mathrm{NaCl})$ and $20 \%{ }^{2} \mathrm{H}$-labelled water. A Carr-Purcell-Meiboom-Gill (CPMG) pulse sequence ${ }^{(27)}$ with water suppression was applied for the acquisition of ${ }^{1} \mathrm{H}$ NMR spectra, with the Carr-Purcell-Meiboom-Gill delay added to attenuate signals from macromolecules. The total spin-spin relaxation delay was $100 \mathrm{~ms}(2 \mathrm{n} \tau)$, the spin-echo delay was $1 \mathrm{~ms}$ and the recycle delay was $2 \mathrm{~s}$. The spectra were acquired by sixty-four scans, 32000 data points, a spectral width of $17 \cdot 34$ parts per million (ppm) and a temperature of $310^{\circ} \mathrm{K}$. A fixed receiver-gain value was used for recording all samples. An exponential line broadening of $0.3 \mathrm{~Hz}$ was applied before Fourier transformation. Each spectrum was manually phased, baseline corrected and referenced to the lactate doublet signal at $1.33 \mathrm{ppm}$ (the reference was checked by the $\alpha$-glucose anomeric doublet at $5 \cdot 23 \mathrm{ppm}$ ). The $\Delta \mathrm{AV}$ spectra were the difference between the ${ }^{1} \mathrm{H}$ spectra of simultaneously collected plasma samples from the portal vein and the mesenteric artery. NMR spectroscopy is a quantitative technique and the $\Delta \mathrm{AV}$ spectra reflected this by showing a mainly positive absorption profile. These positive signals were the result of nutrient uptake from the gastrointestinal tract. The region $0.5-9.0 \mathrm{ppm}$ of the NMR spectra and the $\Delta \mathrm{AV}$ difference was segmented into bins of $0.013 \mathrm{ppm}$ and the integral of each bin was determined. Semi-quantitative absorption values for the bins were calculated by multiplying portal flow measurements to the $\Delta \mathrm{AV}$ according to absorption determination described by Rerat et al. ${ }^{(11)}$. To exclude the water signal, the region $4 \cdot 4-5.0 \mathrm{ppm}$ was not included in the statistical analysis. The betaine signal at $3.26 \mathrm{ppm}$, the $\beta$-glucose signal at $3.24 \mathrm{ppm}$ and the creatine signal at $3.93 \mathrm{ppm}$ were manually integrated.

To aid spectral assignment, two-dimensional (2D) ${ }^{1} \mathrm{H}-{ }^{1} \mathrm{H}$ correlation spectroscopy with double-quantum filter and 2D ${ }^{13} \mathrm{C}-{ }^{1} \mathrm{H}$ heteronuclear single quantum coherence experiments were performed on a representative venous plasma sample using water suppression. The correlation spectroscopy spectra were acquired with a spectral width of $6127 \mathrm{~Hz}$ in both dimensions, 4000 data points, 512 increments with sixty-four transients per increment and a recycle delay of $1.5 \mathrm{~s}$. The heteronuclear single quantum coherence spectra were acquired with a spectral width of $6250 \mathrm{~Hz}$ in the ${ }^{1} \mathrm{H}$ dimension and $21128 \mathrm{~Hz}$ in the ${ }^{13} \mathrm{C}$ dimension, a data matrix with a size of $2048 \times 512$ data points, 256 transients per increment and a recycle delay of $2 \mathrm{~s}$. The ${ }^{13} \mathrm{C}$ chemical shift was referenced to the $\alpha$-glucose anomeric carbon at $94.9 \mathrm{ppm}$.

\section{Amino acid analysis}

Amino acid analysis was carried out using an amino acid analysing kit (Phenomenex ${ }^{\circledR}$ EZ:faast ${ }^{\mathrm{TM}}$ kit; phenomenex, Torrance, CA, USA) and analysed by GC. This analysis was carried out on blood samples collected at $-1,0,0 \cdot 5,1,2,3,4,6,8$ and $10 \mathrm{~h}$ after feeding. The statistical analysis was the same as for the analytical methods described in Serena et al. ${ }^{(24)}$.

\section{Multivariate data analysis}

In the analysis of the NMR data from the plasma samples and the $\Delta \mathrm{AV}$, we used the paired structure in the cross-over design to increase the statistical power. This also allows determining the effect of diet from the within-subject variation by multilevel partial least-squares discriminant analysis (MLPLSDA) ${ }^{(28,29)}$. This approach takes the advantage of the cross-over design study to separate the between-subject from the within-subject variation. Before the multivariate data analysis, the data were Pareto-scaled by dividing each variable by the square root of its standard deviation. For each MLPLSDA model, we used twenty cross-model validations (CMV), which is a double cross-validation where $25 \%$ of the multilevel pairs are randomly selected and used as a test set for the final model for each of the $\mathrm{CMV}^{(30)}$ Variable selection was applied during CMV for model 
optimisation corresponding with 100, 50, 20, 5 and $2 \%$ of all variables $^{(31)}$. To test the significance of the models, permutation testing was performed. In a permutation test, the samples are randomly assigned a label while keeping the number of the two classes the same ${ }^{(28,29,32)}$. For each MLPLSDA model, a thousand permutations were performed to determine the $H_{0}$ distribution of no-effect. The effect was considered significant if the $P$ value was $<0 \cdot 05$. The rank product (RP) was used to select the most discriminating variables $^{(33)}$. The variables were ranked according to the highest absolute regression coefficient for all CMV and multiplied for each of the twenty CMV. To select biomarkers that are favoured more than just by chance, only bins with an RP value below the $20 \%$ significance limit of the RP values from the 1000 permutations were considered to be important bins and therefore discriminating between the two classes.

The algorithms for data pretreatment, MLPLSDA, CMV and permutation tests have been used previously in a study by van Velzen et $a l .{ }^{(28)}$, and they were performed using Matlab (version 2009a; The MathWorks, Inc., Natick, MA, USA) and in-house written Matlab routines. These routines are available via the Internet at http://www.bdagroup.nl/.

(A)

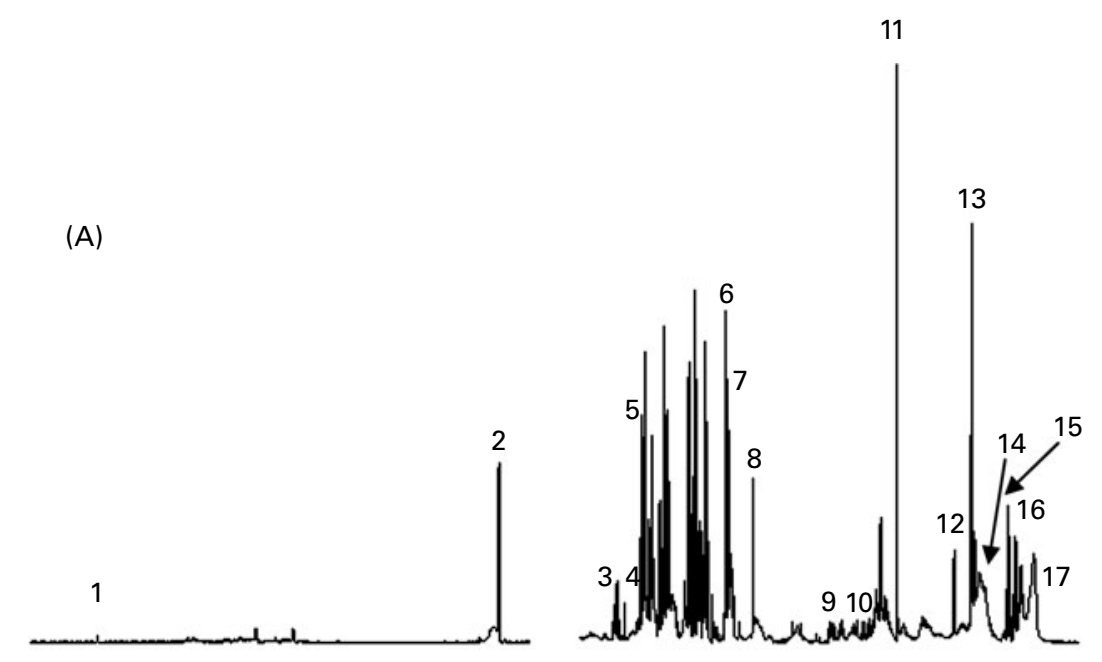

(B)

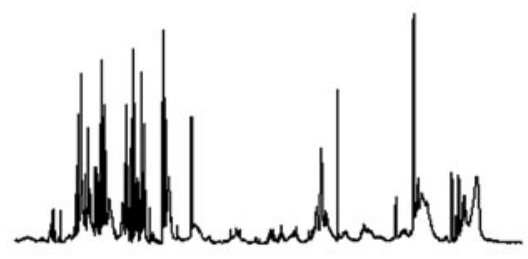

(C)

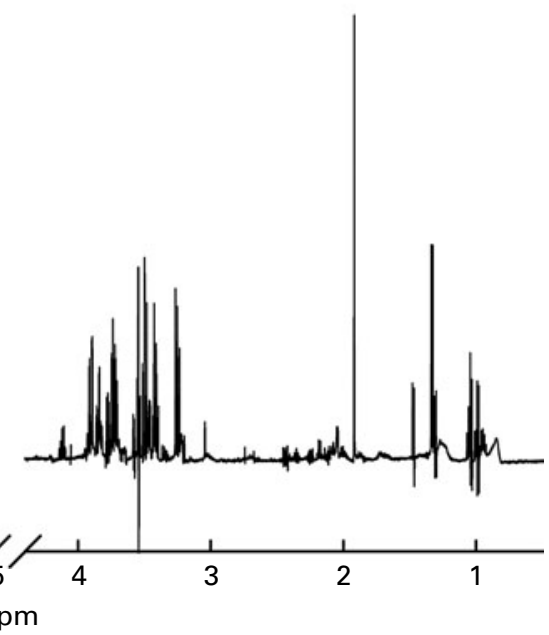

Fig. 1. ${ }^{1} \mathrm{H}$ NMR spectra of plasma samples taken from the (A) portal vein and the (B) mesentery artery of a representative sow $1 \mathrm{~h}$ after feeding on a high-fibre insoluble diet. The spectral difference between (B) mesenteric artery and (A) portal vein plasma samples was determined by (C) subtraction. Assignments are shown in spectra A as follows (multiplicity in parenthesis): 1, formate (singlet, s); 2, $\alpha$-glucose (doublet, d); 3, lactate (quartet, q); 4, creatinine (s); 5, creatine (s); 6, betaine (s); 7, $\beta$-glucose; 8, overlapping peaks for creatine (s) and creatinine (s); 9, unassigned peak (s); 10, propionate (q); 11, acetate (s); 12, alanine (d); 13 , lactate (d); $14, \mathrm{CH}_{2}$ in lipids (multiplet, $\mathrm{m}$ ); 15 , propionate (triplet); 16 , isoleucine, leucine and valine region; $17, \mathrm{CH}_{3}$ in lipids (m). ppm, Parts per million. 
Table 3. Resonance assignments of the compounds listed in Fig. 1 and as detailed in the text

\begin{tabular}{lccll}
\hline Fig. no. & ${ }^{1} \mathrm{H}(\mathrm{ppm})$ & Multiplicity & ${ }^{13} \mathrm{C}(\mathrm{ppm})$ & Assignments \\
\hline 1 & 8.46 & $\mathrm{~s}$ & & Formate \\
2 & 5.24 & $\mathrm{~d}$ & 95.0 & $\alpha$-Glucose, $\mathrm{H} 1$ \\
3 & 4.11 & $\mathrm{q}$ & 71.3 & Lactate, $\mathrm{CH}$ \\
4 & 4.06 & $\mathrm{~s}$ & 59.2 & Creatinine, $\mathrm{CH}_{2}$ \\
5 & 3.93 & $\mathrm{~s}$ & 56.8 & Creatine, $\mathrm{CH}_{2}$ \\
& 3.88 & $\mathrm{~s}$ & 69.3 & Betaine, $\mathrm{CH}_{2}$ \\
& 3.52 & $\mathrm{~s}$ & 44.9 & Gly, $\mathrm{CH}_{2}$ \\
6 & 3.26 & $\mathrm{~s}$ & 56.4 & Betaine, $\mathrm{N}^{\left(\mathrm{CH}_{3}\right)_{3}}$ \\
7 & 3.25 & dd & 76.8 & -Glucose, $\mathrm{H}_{2}$ \\
& 3.22 & $\mathrm{~s}$ & 56.4 & Choline, $\mathrm{N}_{3} \mathrm{CH}_{3}$ \\
8 & 3.05 & $\mathrm{~s}$ & 33.1 & Creatinine, $\mathrm{CH}_{3}$ \\
8 & 3.04 & $\mathrm{~s}$ & 39.9 & Creatine, $\mathrm{CH}_{3}$ \\
10 & 2.18 & $\mathrm{q}$ & & Propionate, $\mathrm{CH}_{3}$ \\
11 & 1.92 & $\mathrm{~s}$ & 26.2 & Acetate, $\mathrm{CH}_{3}$ \\
12 & 1.48 & $\mathrm{~s}$ & 19.7 & Ala, $\mathrm{CH}_{3}$ \\
13 & 1.33 & $\mathrm{~d}$ & 23.0 & Lactate, $\mathrm{CH}_{3}$ \\
14 & 1.27 & $\mathrm{~m}$ & $22.2,25.5,32.4$ & $\mathrm{CH}_{2}$ in lipids \\
15 & 1.06 & $\mathrm{t}$ & & Propionate, $\mathrm{CH}_{2}$ \\
17 & 0.85 & $\mathrm{~m}$ & $16.9,25.5$ & $\mathrm{CH}_{3}$ in lipids \\
\hline
\end{tabular}

ppm, Parts per million; s, singlet; d, doublet; q, quartet; dd, double doublet; $\mathrm{m}$, multiplet; $\mathrm{t}$, triplet.

\section{Univariate data analysis}

ANOVA was performed on the important bins and their absorption values selected as biomarkers in the MLPLSDA models. ANOVA is a univariate method that does not take covariance between the bins into account. However, a linear mixed model with PROC MIXED in the SAS statistical software package version 9.1 (SAS Institute, Cary, NC, USA) was carried out to obtain a model with all diet and time effects and the interaction between diet and time in one model. First, model 1 including the blood compartment (arterial or venous) as a fixed effect was performed on all samples for each of the selected important bins, which tested whether there was a significant difference between the arterial and venous samples (i.e. absorption). Second, model 2 was used to analyse the portal levels of all selected important bins, and whether model 1 showed a significant difference between the venous and arterial samples, and then the important bin absorption values were also analysed.

$$
X_{i j k l m}=\mu_{j}+\alpha_{j k}+\beta_{j l}+\gamma_{j m}+\alpha \beta_{j k l}+\varepsilon_{i j k l m},
$$

where $i=1, \ldots, 6$ for the sows; $j$ is an important bin; $k=1, \ldots, 4$ for the time points; $l=1,2,3$ for the diets; $m=1,2$ for the blood compartments. $\mu_{j}$ is the overall offset for the bin $j ; \alpha_{j k}$ is the overall time effect; $\beta_{j l}$ is the diet effect; $\gamma_{j m}$ is the blood compartment; $\alpha \beta_{j k l}$ is a two-factorial interaction between time and diet; $\varepsilon_{i j k l m}$ is the error term. $X_{i j k l m}$ represents the NMR signal for the sow $i$, at the bin $j$, for the time point $k$, for the diet $l$ and for the blood compartment $m$.

$$
X_{i j k l}=\mu_{j}+\alpha_{j k}+\beta_{j l}+\alpha \beta_{j k l}+\varepsilon_{i j k l},
$$

where $i=1, \ldots, 6$ for the sows; $j$ is an important bin or its absorption value; $k=1, \ldots, 4$ for the time points; $l=1,2,3$ for the diets. $\mu_{j}$ is the overall offset for the bin $j ; \alpha_{j k}$ is the time effect; $\beta_{j l}$ is the diet effect; $\alpha \beta_{j k l}$ is a two-factorial interaction between time and diet; $\varepsilon_{i j k l}$ is the error term. $X_{i j k l}$ represents the NMR signal or the absorption value for the sow $i$, at the bin $j$, for the time point $k$ and for the diet $l$.

Random effects for both models were sow, interaction of diet and week, and the interaction of sow and time. The longitudinal data were modulated using a heterogeneous autoregressive covariance ${ }^{(34)}$ structure when the first model showed a significant difference between the arterial and venous samples (blood compartment). With no difference, indicating no absorption, a uniform covariance structure (compound symmetry ${ }^{(35)}$ ) was used for the plasma levels because we assume that the correlations between the sampling points are the same. The sampling point $0 \mathrm{~h}$ after feeding was presumed to be a $24 \mathrm{~h}$ after feeding sample in the statistical analysis because of the higher correlation between 10 and $24 \mathrm{~h}$ samples than between 0 and $1 \mathrm{~h}$. Least square means were compared by applying the probability of difference procedure of SAS. All $P$ values reported are for two-sided tests, and significance level was set at $\alpha<0 \cdot 05$.

\section{Results}

${ }^{1} \mathrm{H}$ NMR spectra of plasma samples collected from the portal vein had in general higher intensities than spectra from simultaneously collected mesenteric artery plasma samples, as illustrated in Fig. 1(A) and (B) for sampling of a HFI-fed pig $1 \mathrm{~h}$ after feeding (see also Table 3). This demonstrates that differences in absorption can be seen from the $\Delta \mathrm{AV}$ spectra with positive intensities for most metabolites (Fig. 1(C)). The negative resonance at $3.54 \mathrm{ppm}$ arises from glycine and is due to shift in resonance frequency between the arterial and venous samples contributing to different bins. Fig. 2 shows the region $3 \cdot 19-3 \cdot 30 \mathrm{ppm}$ with assignments of a betaine (singlet), $\beta$-glucose (doublet) and signals of choline-containing compounds. A slight shoulder is seen on the betaine signal from protons of three methyl groups. This was assigned

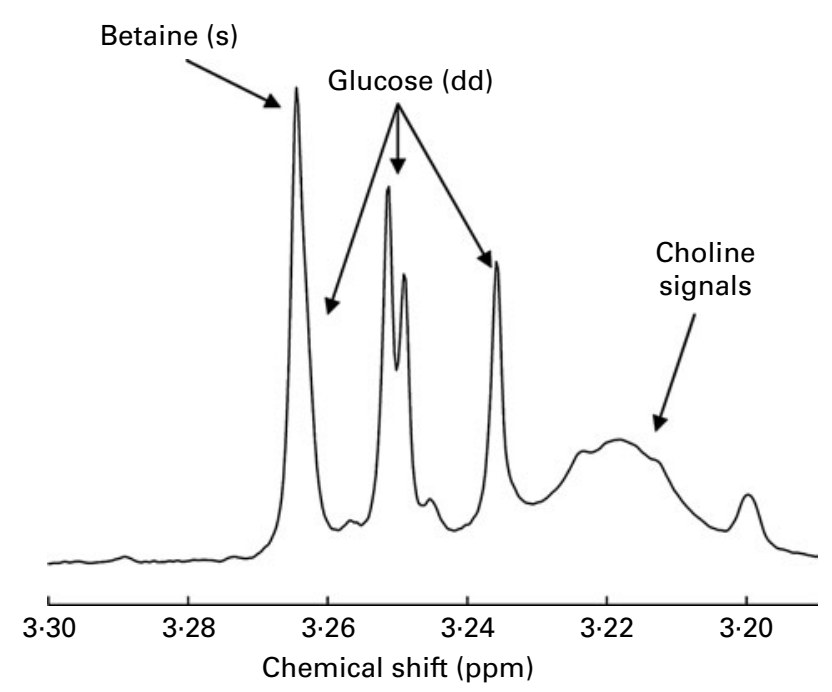

Fig. 2. Expanded region in the ${ }^{1} \mathrm{H}$ NMR spectra of Fig. $1(\mathrm{~A})$ from a representative plasma sample showing signals from betaine, glucose and choline. s, singlet; dd, double doublet; ppm, parts per million. 

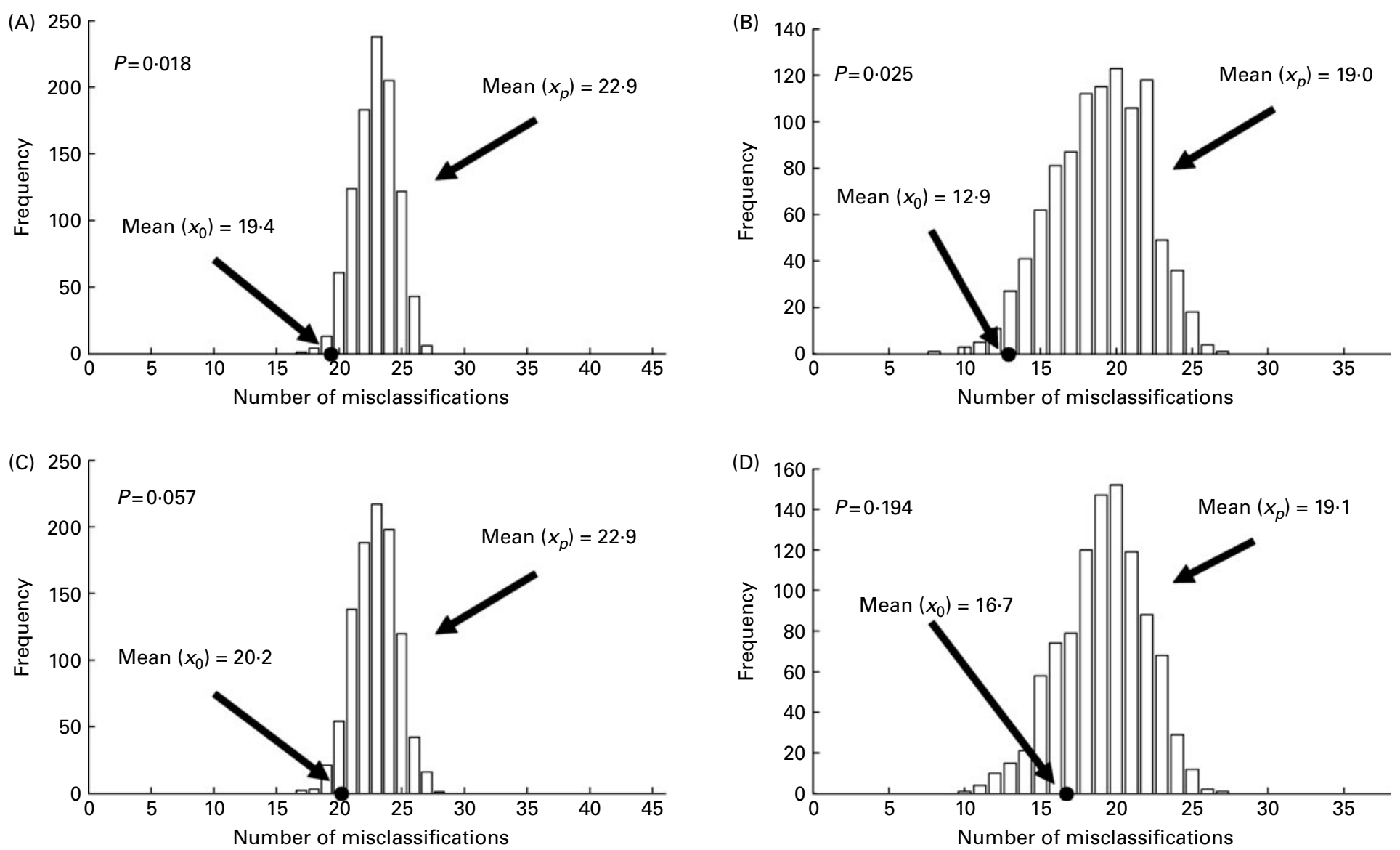

Fig. 3. Number of misclassifications of the mean cross-model validation and the $H_{0}$ distribution of no-effect determined by permutation testing with 1000 permutations. (A) Multilevel partial least-squares discriminant analysis (PLSDA) model for all venous samples and the (B) arterial-venous difference ( $A$ AV) when feeding the high-fibre soluble (HFS) and high-fibre insoluble (HFI) diets. (C) Ordinary PLSDA model for all venous samples and the (D) $\triangle \mathrm{AV}$ when feeding the HFS and HFI diets. 
(A) 1000

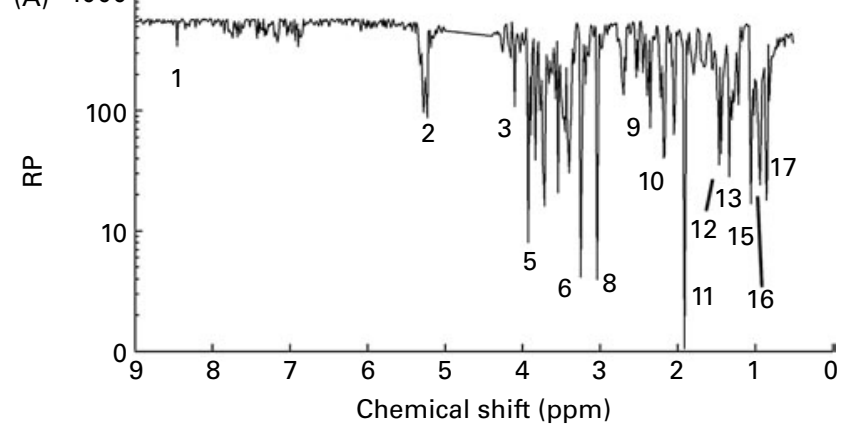

(B) 1000

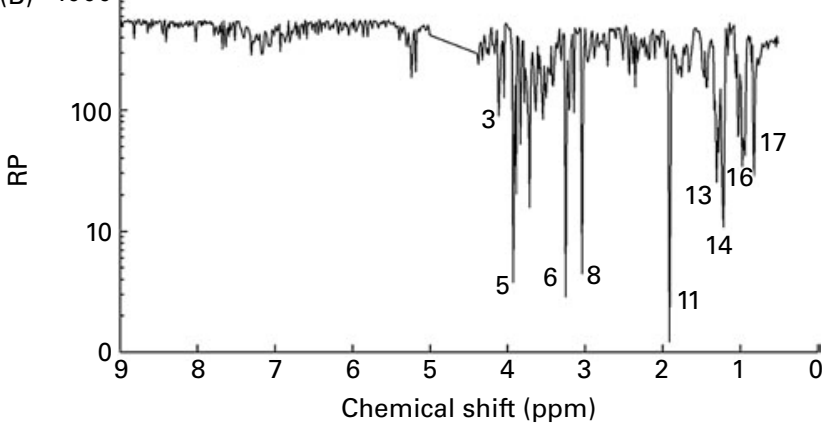

(C) 1000

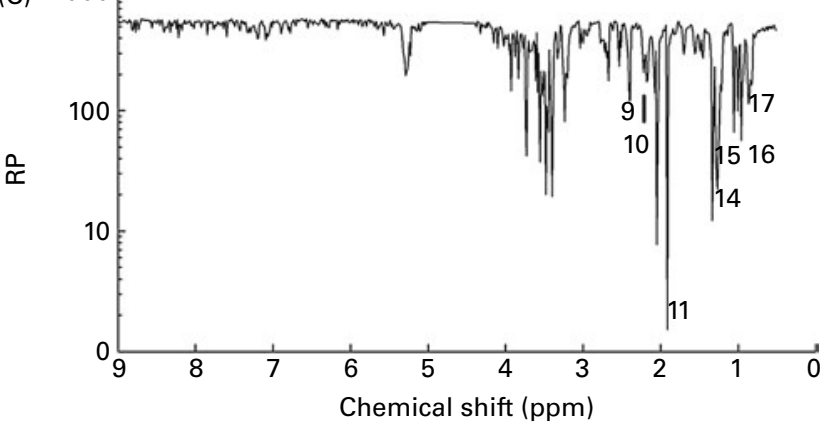

Fig. 4. Rank product $\left(\mathrm{RP}^{1 / 20}\right)$ from multilevel partial least-squares discriminant analysis models of venous samples from comparison (A) between the high-fibre soluble and low-fibre (LF) diets, (B) between the high-fibre insoluble and LF diets and $(C)$ between the two high-fibre diets. The nomenclature is the same as in Fig. 1: 1, formate; 2, $\alpha$-glucose; 3, lactate; 5, creatine; 6 , betaine; 8 , creatine/creatinine; 9 , unassigned peak; 10 , propionate; 11 , acetate; 12 , alanine; 13 , lactate; $14, \mathrm{CH}_{2}$ in lipids; 15 , propionate; 16 , isoleucine, leucine and valine region; $17, \mathrm{CH}_{3}$ in lipids. Only bins with an RP value below the $20 \%$ significance limit of the RP values from the 1000 permutations have been numbered. ppm, Parts per million.

to one of the lines from a doublet of doublets of $\beta$-glucose with $J$ couplings of 8.7 and $8.0 \mathrm{~Hz}$.

MLPLSDA was performed on Pareto-scaled within-subject data to elucidate the biochemical dissimilarities of feeding the different experimental diets. In Fig. 3, the mean CMV prediction error based on twenty CMV is compared with 1000 permutations under the $H_{0}$ distribution for all venous samples and the $\triangle \mathrm{AV}$ when the sows are fed the HFS or HFI diet at all sampling points. Only one venous sample was missing; thus, there were twenty-three multilevel pairs out of twenty-four multilevel pairs. A CMV prediction error of 19.4 misclassifications and an average of the permutation of 22.9 misclassifications were found for the MLPLSDA model in Fig. 3(A) of the venous samples, and the classification result was significant $(P=0 \cdot 018)$. The ordinary PLSDA model did not result in a significant diet effect between the two diets (Fig. 3(C); $P=0.057$ ). To calculate a MLPLSDA model of the $\triangle \mathrm{AV}$ data, thirty-eight out of forty-eight samples were used because of one missing venous sample and four missing arterial samples and the need for a corresponding sample to determine the $\Delta \mathrm{AV}$ difference. Data analysis of the $\triangle \mathrm{AV}$ did also show a significant diet effect with the MLPLSDA model $(P=0.025)$, whereas the ordinary PLSDA model did not indicate a significant diet effect $(P=0 \cdot 19)$. When using MLPLSDA to compare the diet effect between the LF and the high-fibre diets, all models for venous samples and the $\Delta \mathrm{AV}$ were highly significant $(P<0 \cdot 001$; data not shown).

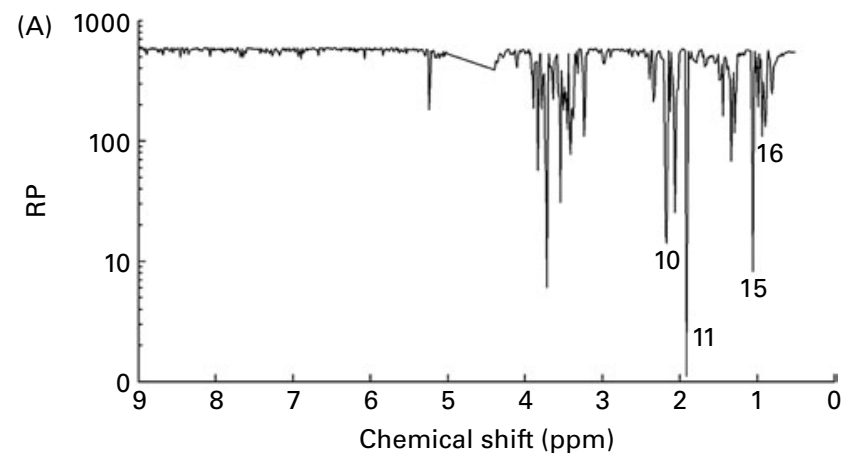

(B) $1000_{E}$

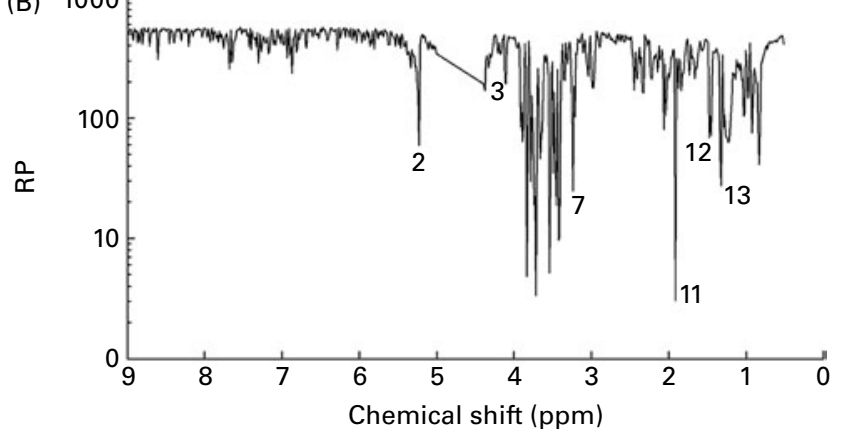

(C) 1000

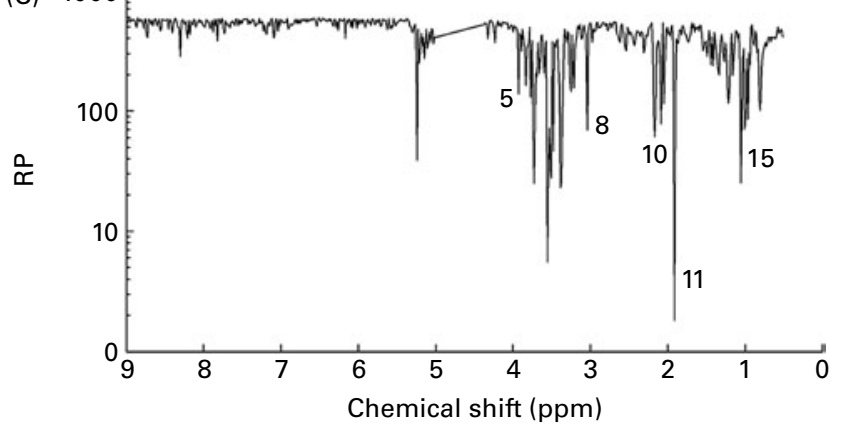

Fig. 5. Rank product $\left(\mathrm{RP}^{1 / 20}\right)$ from multilevel partial least-squares discriminant analysis models of the arterial-venous difference $(\triangle A V)$ from comparison (A) between the high-fibre soluble and low-fibre (LF) diets, (B) between the high-fibre insoluble and LF diets and (C) between the two high-fibre diets. The nomenclature is the same as in Fig. 1: 2, $\alpha$-glucose; 3, lactate; 5, creatine; $7, \beta$-glucose; 8 , creatine/creatinine; 10 , propionate; 11 , acetate; 12 , alanine; 13 , lactate; 15 , propionate; 16 , isoleucine, leucine and valine region. Only bins with an RP-value below the $20 \%$ significance limit of the RP values from the 1000 permutations have been numbered. ppm, Parts per million. 
The rank product was used to identify valid biomarkers in the plasma between sows fed the experimental diets. The variables with the lowest rank are the most discriminating between the two classes. To eliminate false-positive biomarkers, only the RP values below the $20 \%$ significance limit in comparison with the RP values obtained by the permutations were selected from Figs. 4 and 5. The most discriminating rank products in Fig. 4(A) show that formate, glucose, lactate, creatine, betaine, creatine/creatinine $(3.04 \mathrm{ppm})$, pyruvate, propionate, acetate, alanine, the isoleucine/leucine/ valine region and lipid signal at $0.86 \mathrm{ppm}$ differentiate between feeding the LF and the HFS diets in the venous plasma. The metabolites in venous samples found to vary between HFI- and LF-fed sows were lactate, creatine, betaine, creatine/creatinine (3.04 ppm), acetate, lipid signal at 0.82 and $1.21 \mathrm{ppm}$, and the isoleucine/leucine/valine region (Fig. 4(B)). As shown in Fig. $4(\mathrm{C})$, pyruvate, propionate, acetate, lipid signal at 0.87 and $1.27 \mathrm{ppm}$, and the isoleucine/leucine/ valine region discriminate between the two high-fibre diets, HFS and HFI, in the venous samples. Fig. 5 illustrates the variation in $\Delta \mathrm{AV}$ between feeding the different diets. The rank product for variables ascribed to propionate, acetate and the isoleucine/leucine/valine region was found to discriminate between the $\Delta \mathrm{AV}$ of the HFS- and the LF-fed sows (Fig. 5(A)). Fig. 5(B) indicates that glucose, acetate, alanine and lactate are biomarkers for the classification between the $\Delta \mathrm{AV}$ when feeding the HFI and LF diets. Metabolites differentiating in $\Delta \mathrm{AV}$ between the two high-fibre diets, HFS and HFI, are creatine, creatine/creatinine $(3.04 \mathrm{ppm})$, propionate and acetate (Fig. $5(\mathrm{C})$ ). The bin at $3.04 \mathrm{ppm}$ contains the signal from two partly overlapping singlets of creatine and creatinine. The MPLSDA of Figs. 3 and 4 did indicate variation for the creatine singlet at $3.93 \mathrm{ppm}$ and no variation for the creatinine singlet at $4.06 \mathrm{ppm}$. Therefore, variation of the bin at $3.04 \mathrm{ppm}$ can be ascribed to creatine. The region between 3.3 and $3.9 \mathrm{ppm}$ also contains important variables in the MLPLSDA models that correspond to overlapping signals from protons in glucose and amino acids (mainly $\alpha$-protons).

MPLSDA revealed numerous biomarkers of the biochemical differences in venous samples and the $\Delta \mathrm{AV}$ between the diets. These biomarkers were tested in an ANOVA model for the venous plasma levels and the absorption value as the $\Delta \mathrm{AV}$ multiplied by the blood flow. Isoleucine, leucine and valine were not tested in the ANOVA model because of an overlap with the lipid signal and some chemical shifting of these peaks in the NMR spectra that can cause variation. In Table 4 , the significance of these bins and their contrasts are shown, together with the ratio of the intensity:absorption value divided by the lowest intensity:absorption value. The ratio reflects the quantitative relationship between protons from a specific metabolite in a bin, i.e. for venous samples the least square means of acetate show that LF-fed sows have the lowest acetate concentrations and that HFS- and HFI-fed sows have 129 and $79 \%$ higher concentrations, respectively $(P<0 \cdot 0001)$. The least square means of acetate venous plasma concentrations were significantly different for all three experimental diets. If no significant difference between the arterial and venous samples exists, only the data for the venous plasma are included in Table 4, as this suggests that no uptake of nutrients is likely to occur. A significant diet effect on venous plasma samples between the two high-fibre- and the low-fibre-fed sows was found for betaine $(P=0 \cdot 008)$, creatine $(P=0 \cdot 020)$ and glucose $(P=0 \cdot 010)$. A significant difference between $0 \mathrm{~h}$ and the rest of the sampling

Table 4. ANOVA of important bins and absorption values*

\begin{tabular}{|c|c|c|c|c|c|c|c|c|c|c|c|}
\hline & \multirow[b]{2}{*}{ Bin (ppm) } & \multicolumn{3}{|c|}{ Diet } & \multirow[b]{2}{*}{$P$} & \multicolumn{4}{|c|}{ Time } & \multirow[b]{2}{*}{$P$} & \multirow{2}{*}{$\begin{array}{c}\text { Diet } \times \text { time } \\
P\end{array}$} \\
\hline & & LF & HFS & $\mathrm{HFI}$ & & $\mathrm{Oh}$ & $1 \mathrm{~h}$ & $4 \mathrm{~h}$ & $10 \mathrm{~h}$ & & \\
\hline \multicolumn{12}{|l|}{ Ala } \\
\hline Venous & 1.46 & $1 \cdot 27^{\mathrm{a}}$ & $1 \cdot 00^{\mathrm{b}}$ & $1.06^{\mathrm{ab}}$ & 0.046 & $1.00^{b}$ & $1 \cdot 70^{\mathrm{a}}$ & $1.64^{\mathrm{a}}$ & $1 \cdot 23^{b}$ & 0.0079 & 0.67 \\
\hline Absorption & & $2 \cdot 15$ & 1.00 & 1.25 & 0.098 & $3.65^{b}$ & $10 \cdot 0^{a}$ & $15 \cdot 3^{\mathrm{a}}$ & $1.00^{\mathrm{b}}$ & 0.0021 & 0.29 \\
\hline \multicolumn{12}{|l|}{ Acetate } \\
\hline Venous & 1.91 & $1.00^{\mathrm{C}}$ & $2 \cdot 29^{\mathrm{a}}$ & $1.79^{\mathrm{b}}$ & $<0.0001$ & 1.09 & 1.00 & 1.21 & 1.19 & 0.13 & 0.74 \\
\hline Absorption & ז & $1.00^{\mathrm{b}}$ & $2 \cdot 50^{\mathrm{a}}$ & $1.50^{\mathrm{b}}$ & 0.027 & 1.21 & 1.00 & 1.41 & 1.05 & 0.58 & 0.77 \\
\hline \multicolumn{12}{|l|}{ Propionate } \\
\hline Venous & $2 \cdot 18$ & $1.00^{\mathrm{b}}$ & $1.65^{\mathrm{a}}$ & $1 \cdot 25^{\mathrm{b}}$ & 0.017 & $1 \cdot 14$ & 1.00 & 1.22 & $1 \cdot 28$ & 0.19 & 0.76 \\
\hline Absorption & & $1.00^{\mathrm{b}}$ & $2 \cdot 07^{a}$ & $1 \cdot 19^{b}$ & 0.0011 & 1.38 & 1.00 & 1.45 & 1.41 & 0.20 & 0.68 \\
\hline \multicolumn{12}{|l|}{ Betaine } \\
\hline Venous & 3.25 & $1.28^{\mathrm{a}}$ & $1.00^{\mathrm{b}}$ & $1.03^{\mathrm{b}}$ & 0.008 & $1.00^{\mathrm{b}}$ & $1.40^{\mathrm{a}}$ & $1.32^{\mathrm{a}}$ & $1.25^{\mathrm{a}}$ & 0.0014 & 0.11 \\
\hline Absorption & & 1.71 & 1.00 & 1.03 & 0.42 & $1.00^{b}$ & $22 \cdot 9^{\mathrm{a}}$ & $16 \cdot 5^{\mathrm{a}}$ & $5 \cdot 73^{b}$ & 0.0005 & 0.38 \\
\hline \multicolumn{12}{|l|}{ Creatine } \\
\hline Venous & 3.93 & $1.47^{\mathrm{a}}$ & $1.00^{\mathrm{b}}$ & $1.07^{b}$ & 0.020 & $1.00^{b}$ & $1 \cdot 17^{a}$ & $1 \cdot 13^{a}$ & $1 \cdot 14^{\mathrm{a}}$ & 0.048 & 0.70 \\
\hline \multicolumn{12}{|l|}{ Lactate } \\
\hline Venous & $4 \cdot 10$ & 1.00 & 1.05 & $1 \cdot 12$ & 0.26 & $1.00^{C}$ & $1.47^{\mathrm{a}}$ & $1.21^{\mathrm{b}}$ & $1 \cdot 15^{\mathrm{bc}}$ & 0.0083 & 0.67 \\
\hline Absorption & & 1.00 & 1.30 & 1.69 & 0.27 & $1.00^{\mathrm{b}}$ & $3.92^{\mathrm{a}}$ & $3.76^{a}$ & $3.04^{\mathrm{a}}$ & 0.014 & 0.86 \\
\hline \multicolumn{12}{|l|}{ Glucose } \\
\hline Venous & $5 \cdot 23$ & $1 \cdot 22^{\mathrm{a}}$ & $1.00^{\mathrm{b}}$ & $1.06^{\mathrm{b}}$ & 0.010 & $1.00^{c}$ & $1.66^{\mathrm{a}}$ & $1 \cdot 37^{\mathrm{b}}$ & $1 \cdot 29^{\mathrm{b}}$ & $<0.0001$ & 0.18 \\
\hline Absorption & & $2 \cdot 47^{\mathrm{a}}$ & $1.00^{\mathrm{b}}$ & $1 \cdot 18^{\mathrm{b}}$ & 0.018 & $1.00^{c}$ & $10 \cdot 81^{a}$ & $6 \cdot 41^{\mathrm{ab}}$ & $3.45^{\mathrm{bc}}$ & 0.0003 & $0 \cdot 16$ \\
\hline \multicolumn{12}{|l|}{ Formate } \\
\hline Venous & 8.45 & 1.47 & 1.00 & 1.00 & 0.16 & $1.00^{\mathrm{c}}$ & $1 \cdot 17^{\mathrm{C}}$ & $2 \cdot 43^{\mathrm{a}}$ & $1.73^{b}$ & $<0.0001$ & 0.23 \\
\hline
\end{tabular}

ppm, Parts per minute.

a,b,c Least-square mean values within a row with unlike superscript letters were significantly different for the diet or time effects $(P<0.05)$

* The effects are determined as the intensity:absorption value divided by the lowest intensity:absorption value. 
points was found for both betaine $(P=0.0014)$ and creatine $(P=0.048)$. The betaine time profile showed a significant higher absorption in the absorptive phase $(P=0.0005)$. Creatine did not have a significant difference between the venous and arterial samples, indicating no absorption of creatine. Glucose absorption was highest in the absorptive phase ( 1 and $4 \mathrm{~h} ; P<0.0001)$ and when the sows were fed the LF diet $(P=0 \cdot 010)$. The SCFA acetate $(P<0 \cdot 0001)$ and propionate $(P<0 \cdot 017)$ were in the order HFS $>$ HFI $>$ LF in the venous samples, and the numerical values of the absorption values did reflect this order, but only the absorption values for HFS-fed sows were significantly different from the other experimental diets ( $P=0.027$ for acetate; $P=0.0011$ for propionate). The SCFA were not affected by time. Significant diet effects on venous plasma levels were found for alanine, with a high concentration when feeding the LF diet, intermediate when feeding the HFI diet and low when feeding the HFS diet $(P=0 \cdot 046)$. Venous alanine concentrations were high in the absorptive phase ( 1 and $4 \mathrm{~h}$ ) and low in the post-absorptive phase $(10 \mathrm{~h})$ and before feeding (0 h; $P=0.0079)$. Absorption was not significantly affected by diet $(P=0.098)$; however, the time profile was similar to concentration in the venous samples $(P=0.0021)$. There was no significant diet effect for lactate $(P=0 \cdot 26)$. However, lactate did vary between the sampling points with a high venous plasma concentration at $1 \mathrm{~h}$ and a low concentration at 0 and $10 \mathrm{~h}(P=0 \cdot 0083)$. Absorption of lactate was significantly different between $0 \mathrm{~h}$ and the rest of the sampling points $(P=0 \cdot 014)$. There was no indication of the absorption of formate. Formate concentrations in venous samples were high at $4 \mathrm{~h}$, intermediate at $10 \mathrm{~h}$ and low at 0 and $1 \mathrm{~h}(P<0 \cdot 0001)$, and no significant diet effect was found for formate venous concentrations $(P=0 \cdot 16)$. Also, no significant effects were found for pyruvate.

The amino acid analysis revealed a significant time effect on alanine $(P<0 \cdot 0001)$ and glycine $(P=0.025)$ but no significant diet or diet $x$ time interaction effects. The time profiles for alanine, glycine and methionine plasma venous concentrations and methionine absorption, as determined by GC, can be found in Table 5. For venous plasma concentrations, $P$ values of methionine were $P=0.0028$ for diet and $P<0.0001$ for time and for the absorption of methionine, $P=0.0012$ for time and the diet effect was non-significant. There was too much overlap from an unsaturated lipid signal to determine the variation of the methionine singlet at $2 \cdot 14 \mathrm{ppm}$ by NMR spectroscopy. Due to overlapping in the glucose region, it was also not possible to determine the variation of glycine at $3.54 \mathrm{ppm}$.

The betaine peak at $3.26 \mathrm{ppm}$ and the creatine peak at $3.93 \mathrm{ppm}$ were manually integrated and the betaine integral was subtracted from the integral of the upfield $\beta$-glucose doublet of doublets line at $3.24 \mathrm{ppm}$. Fig. 6 shows the results of the venous betaine and creatine levels for all sows and each of the three diets. The venous betaine levels seem to indicate a slow increase of betaine in the portal vein and higher levels when feeding the LF diet. The venous creatine integrals clearly show a general trend for higher creatine concentration when feeding the LF diet without any sign of a time effect.

\section{Discussion}

In the present study, the use of NMR spectroscopy for studying absorption dynamics of dietary nutrients was investigated. Previously, the concentrations and absorption of acetate, glucose, lactate and propionate have been measured by traditional analytical methods from the same study ${ }^{(24)}$. These data were carried out on seventeen sampling points, whereas the NMR method was only applied to four sampling points. The ${ }^{1} \mathrm{H}$ NMR data showed the same major trends in the time profiles as the traditional analytical methods. Accordingly, determination of the absorption from the $\Delta \mathrm{AV}$ by NMR spectroscopy and the portal blood flow proved to be an effective way of determining the uptake of nutrients from the gastrointestinal tract. The biochemical changes of these metabolites will not be discussed here but we refer to the studies using the traditional analytical methods ${ }^{(23,24)}$. Other metabolites that showed a large variation in plasma concentration and/ or absorption and were well resolved in the NMR spectra included formate and alanine. Good agreement was found between alanine levels determined by the NMR-based method and by GC, respectively. The plasma concentration and absorption profiles of alanine showed uptake that is characteristic for the small intestine (Fig. 5). Formate is a byproduct of carbon metabolism but it can also be a product of fermentation of DF by the gut microbes. There was no observed absorption, suggesting that the time effect of formate was a result of carbon metabolism.

Table 5. Alanine and glycine portal vein concentrations, and methionine portal vein concentration and absorption*

\begin{tabular}{|c|c|c|c|c|c|c|c|c|c|c|}
\hline & \multicolumn{3}{|c|}{ Diet } & \multirow[b]{2}{*}{$P$} & \multicolumn{4}{|c|}{ Time } & \multirow[b]{2}{*}{$P$} & \multirow{2}{*}{$\begin{array}{c}\text { Diet } \times \text { time } \\
P\end{array}$} \\
\hline & LF & HFS & $\mathrm{HFI}$ & & $\mathrm{Oh}$ & $1 \mathrm{~h}$ & $4 \mathrm{~h}$ & $10 \mathrm{~h}$ & & \\
\hline \multicolumn{11}{|l|}{ Ala } \\
\hline Venous & $1 \cdot 18$ & 1.00 & 1.07 & 0.38 & 1.00 & 1.91 & 1.47 & 1.29 & $<0.0001$ & 0.26 \\
\hline \multicolumn{11}{|l|}{ Gly } \\
\hline Venous & $1 \cdot 15$ & 1.00 & $1 \cdot 16$ & 0.26 & 1.04 & 1.09 & 1.03 & 1.00 & 0.025 & 0.34 \\
\hline \multicolumn{11}{|l|}{ Met } \\
\hline Venous & $1 \cdot 24^{\mathrm{a}}$ & $1.00^{\mathrm{b}}$ & $1.04^{b}$ & $<0.0001$ & 1.01 & 1.59 & $1 \cdot 16$ & 1.00 & $<0.0001$ & 0.18 \\
\hline Absorption & 1.07 & 1.30 & 1.00 & 0.56 & 1.00 & $12 \cdot 77$ & 5.37 & 4.19 & 0.0012 & 0.68 \\
\hline
\end{tabular}



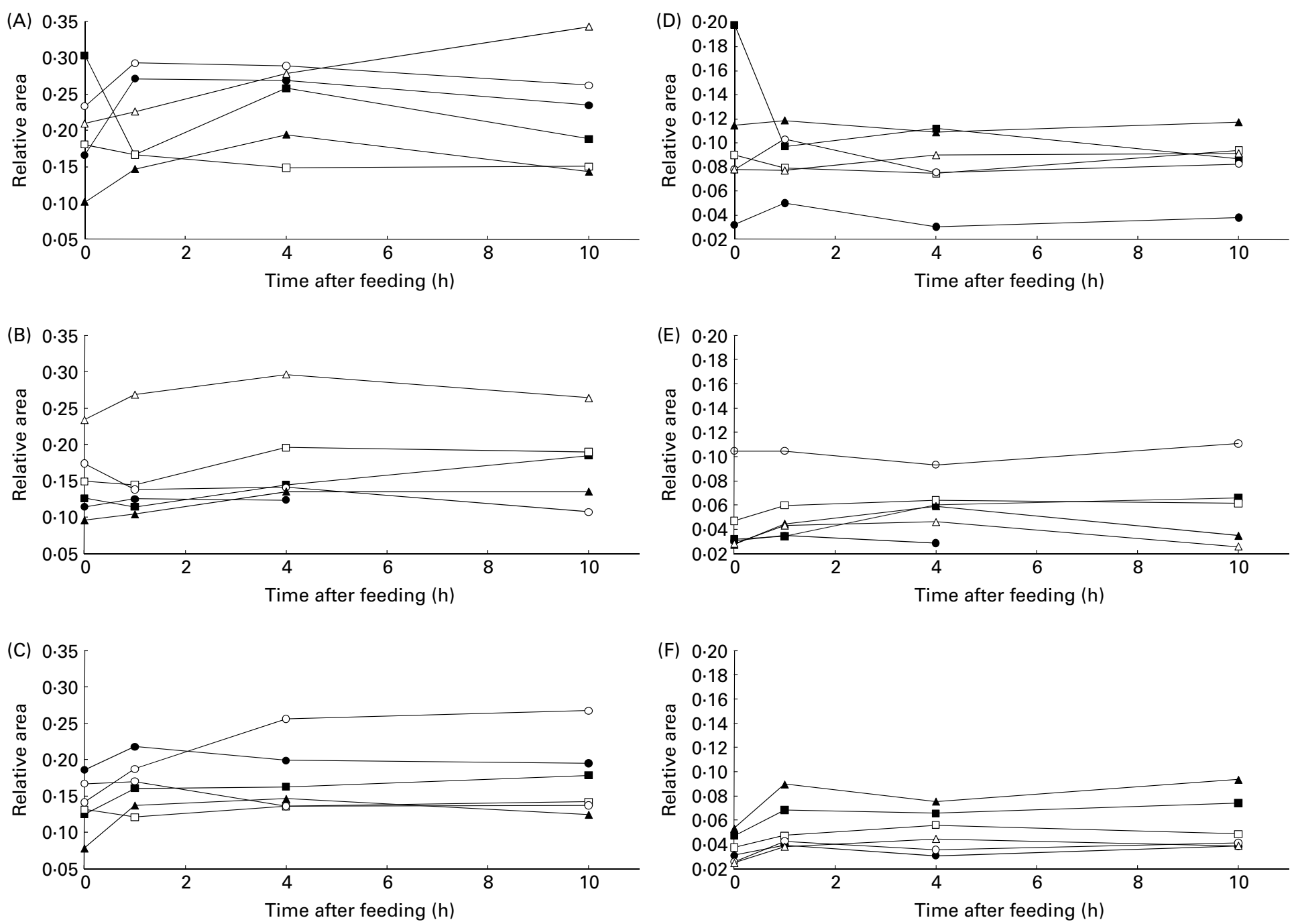

Fig. 6. Plasma $(A-C)$ betaine and $(D-F)$ creatine venous levels for sows fed a $(A, D)$ low-fibre diet, $(B, E)$ high-fibre soluble diet and (C, F) high-fibre insoluble diet. The six sows are marked with different symbols $(\mathrm{O}, \bullet, \Delta, \mathbf{\Lambda}, \square$ and $\mathbf{\square})$. 
Betaine is known to be an effective osmolyte. Another function of betaine is as a methyl donor in the methylation of homocysteine in the methionine cycle, as shown in Fig. 7 (36). It is believed that betaine decreases the concentrations of homocysteine in blood, which is a risk factor for $\mathrm{CVD}^{(37)}$. Thus, betaine can be considered as an important metabolite. The absorption profile of betaine followed basically that of glucose, with a rapid increase in absorption in the absorptive phase at $1 \mathrm{~h}$ after feeding, followed by a steady decline to 4 and $10 \mathrm{~h}$ after feeding for all three diets. There was a diet effect on concentration in plasma with the highest levels when feeding the LF diet $28 \%$ higher concentration in the portal vein when feeding the LF diet than the HFS diet; the HFS and HFI diets had similar portal vein concentrations). This LF diet had a high content of wheat, which is known to have a relatively high amount of betaine ${ }^{(38)}$. LF-fed sows had a higher numerical absorption of betaine, but it was not significant. However, based on the results from the venous samples, a fair assumption is that betaine plasma levels accumulate from the start of the period the sows are fed the LF diet due to increased uptake of betaine.

Creatine is used in vertebrates for energy supply to muscle as stored creatine phosphate. There was no significant $\Delta \mathrm{AV}$ in creatine between the diets in the ANOVA model, indicating no uptake into the portal vein. A plant-based diet would not

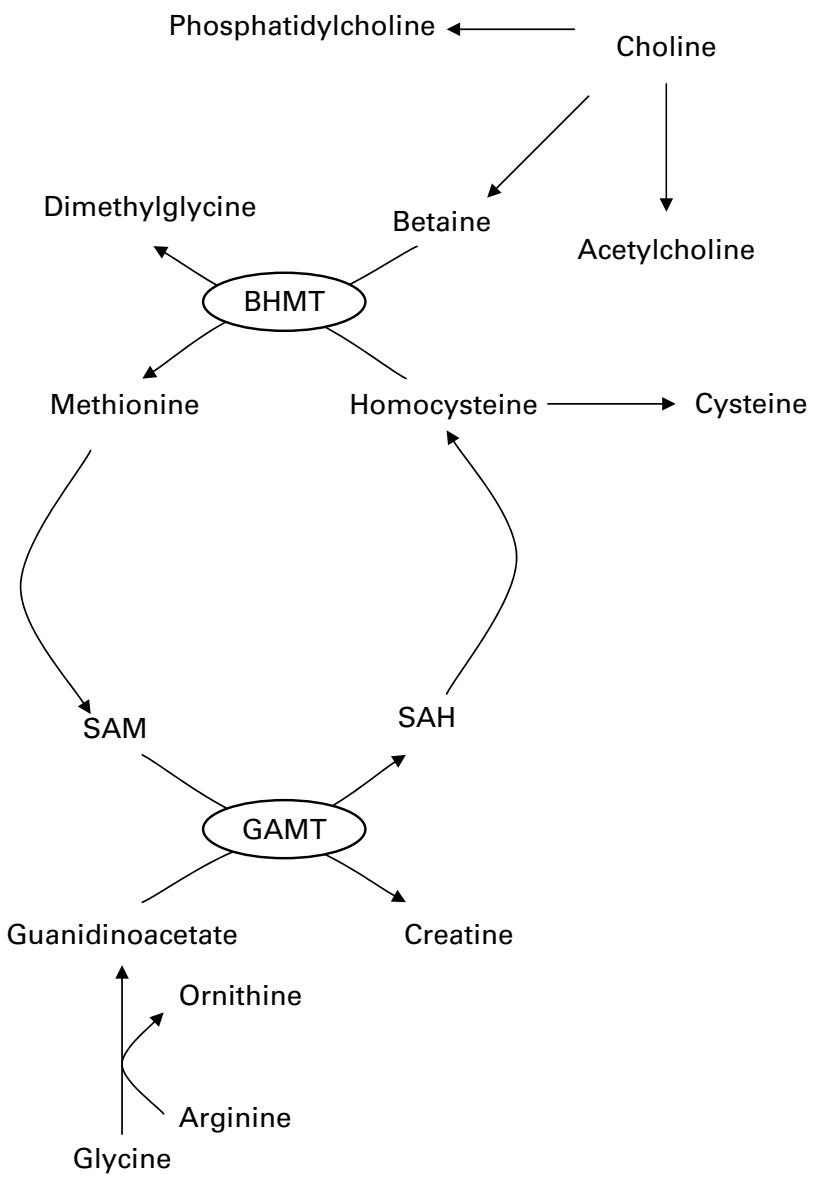

Fig. 7. Pathway for creatine synthesis and related transmethylation. BHMT, betaine-homocysteine methyltransferase; SAM, S-adenosylmethionine; SAH, $S$-adenosylhomocysteine; GAMT, guanidinoacetate methyltransferase. contain creatine and the creatine levels in the blood of the sows are synthesised de novo in the liver mainly by the use of arginine, glycine and methionine ${ }^{(39)}$. An interesting question is whether the elevated levels of creatine seen in the plasma of LF-fed sows increase the creatine phosphate levels in creatine kinase-containing tissues as well, and thereby promoting an increased tissue pool of creatine and creatinine maybe caused by the higher dietary level of starch in the LF diet compared with the two high-DF diets. This could have negative effects when feeding the high-fibre diets. Because the high-fibre soluble and insoluble diets have the same time profile of creatine levels, it would be reasonable to leave out the physico-chemical properties of the diet as the main reason.

Methionine was not well resolved in the NMR spectra (at $2 \cdot 14 \mathrm{ppm}$ ). However, the GC amino acid analysis pointed at significant elevated levels of methionine in the venous samples of the LF diet compared with the high-DF diets. Absorption was not significantly different between the diets. Hence, we found an endogenous methionine variation as an effect of diet.

Numerous metabolites are involved in creatine synthesis, but it is possible to determine the pathways because creatine plasma concentration is of endogenous origin. Increased absorption of betaine can lead to the elevated levels of creatine in plasma, because of the requirement of a methyl donor from $S$-adenosylhomocysteine to synthesis creatine by the methylation of homocysteine (Fig. 7). It has been found in a study on creatine metabolism in piglets that there are relatively high activities of guanidinoacetate methyltransferase in the liver ${ }^{(40)}$. Thus, it has been hypothesised that high betaine absorption when feeding the LF diet causes elevated creatine plasma concentrations. In agreement with the hypothesis, NMR analysis on urine samples from a separate study ${ }^{(26)}$ using the same three diets indicated higher excretion of betaine and creatinine in the urine when feeding the LF diet compared with the high-fibre diets (CC Yde and KE Bach Knudsen, unpublished results). The high methionine plasma concentrations when feeding the LF diet reflected its contribution to methyl donation in the synthesis of creatine. Glycine is a precursor of creatine synthesis, but it showed no diet effect that can explain the diet effect on creatine.

In a study by Hoffman et al. ${ }^{(41)}$, betaine supplementation to human subjects appeared to improve muscle endurance in a squat exercise, which was suggested to be related to increased muscle creatine concentrations. The relationship between the high content of betaine in the LF diet and the elevated plasma creatine concentration may indicate a performance relationship between the formulation of the diet and the endurance. Further studies are needed for determining a clear link. It has been found that a whole-grain diet compared with a nonwhole-grain diet increases the dietary intake of betaine ${ }^{(17)}$ This leads to increased excretion of creatinine without influencing the portal vein concentration of creatine. The present findings suggest that feeding a diet high in betaine may cause interesting metabolic effects. However, further investigations are needed to determine the importance of feeding different types and levels of DF with regard to creatine 
synthesis. There are also other factors to take into account. Different protein concentrations (low for LF) and daily energy intake (significant lower for HFI) could also influence the outcome. Consequently, a more controlled set-up is needed to directly access the importance of these factors.

The betaine signal at $3.26 \mathrm{ppm}$ overlapped with the downfield line of the doublet of doublets from $\beta$-glucose at $3.25 \mathrm{ppm}$. The glucose levels were highest at $1 \mathrm{~h}$ after feeding, which influence the results by increasing the size of the bin assigned to betaine at $3.25 \mathrm{ppm}$. Consequently, the binning procedure overestimated the betaine levels at mainly $1 \mathrm{~h}$ after feeding. Determination of the venous betaine levels from the integral of the betaine and glucose signal indicated slower betaine absorption than found by the bins. Unfortunately, the other betaine signal from the $\mathrm{CH}_{2}$ protons at $3.89 \mathrm{ppm}$ was heavily overlapped from the glucose signal. A special issue concerning the $\Delta \mathrm{AV}$ was the low signal:noise ratio of the $\Delta \mathrm{AV}$ spectra, which may reduce reliability. Improvement of the method could be achieved by removing the lipoproteins, as the interactions between metabolites and lipoprotein cause line broadening, and overlap from lipoprotein signals strongly reduces the resolution. An approach to deal with these difficulties is diffusion $\mathrm{NMR}^{(42)}$. Diffusion NMR is a technique that enables distinguishing between the signals from low-molecular-weight compounds from largemolecular-weight compounds. Another method is the physical removal of the lipoprotein by extraction or ultrafiltration ${ }^{(43)}$.

\section{Conclusion}

The main purpose of the present study was to determine the absorption of specific metabolites without bias towards a specific metabolite, which proved to complement the findings from traditional analytical methods. Furthermore, the absorption profiles determined from ${ }^{1} \mathrm{H}$ NMR-based metabonomics revealed new insight into the effects of feeding different types and levels of DF. A low-fibre diet resulted in elevated concentrations of creatine, which was shown to be of endogenous origin. In addition, the elevated concentration of creatine was related to the uptake of betaine, which is known to have health-promoting homocysteine-lowering effects. Thus, by using this explorative approach, we could determine the biochemical changes from unexpected findings of variation in hundreds of metabolites by a multivariate technique.

\section{Acknowledgements}

The authors are grateful to the work carried out by Anja Serena. This includes animal handling, sampling and the traditional analytical measurements. The authors would like to thank the technical staff for assistance. The Danish Technology and Production Research Council (FTP) is thanked for financial support through the project 'Advances in food quality and nutrition research through implementation of metabolomic technologies' and the Danish Agency for Science, Technology and Innovation for co-funding the $\mathrm{PhD}$ project for C. C. Y. The authors' contributions are as follows: C. C. Y. performed the NMR measurements, data analysis and wrote the manuscript. J. A. W. contributed to the statistical work. H. C. B. contributed to the NMR measurements. K. E. B. K. was responsible for the project development. All authors contributed to the reviewing and editing of the manuscript. There are no conflicts of interest.

\section{References}

1. Bach Knudsen KE (2001) The nutritional significance of 'dietary fibre' analysis. Anim Feed Sci Technol 90, 3-20.

2. Danielsen V \& Vestergaard EM (2001) Dietary fibre for pregnant sows: effect on performance and behaviour. Anim Feed Sci Technol 90, 71-80.

3. de Leeuw JA, Bolhuis JE, Bosch G, et al. (2008) Effects of dietary fibre on behaviour and satiety in pigs. Proc Nutr Soc 67, 334-342.

4. Salas-Salvado J, Farres X, Luque X, et al. (2008) Effect of two doses of a mixture of soluble fibres on body weight and metabolic variables in overweight or obese patients: a randomised trial. Br J Nutr 99, 1380-1387.

5. Trowell H (1972) Ischemic-heart disease and dietary fiber. Am J Clin Nutr 25, 926-932.

6. Chandalia M, Garg A, Lutjohann D, et al. (2000) Beneficial effects of high dietary fiber intake in patients with type 2 diabetes mellitus. N Engl J Med 342, 1392-1398.

7. Roberfroid MB (2005) Introducing inulin-type fructans. $\mathrm{BrJ}$ Nutr 93, S13-S25.

8. Solanky KS, Bailey NJC, Holmes E, et al. (2003) NMR-based metabonomic studies on the biochemical effects of epicatechin in the rat. J Agric Food Chem 51, 4139-4145.

9. Wishart DS (2008) Metabolomics: applications to food science and nutrition research. Trends Food Sci Technol 19, $482-493$.

10. Nicholson JK, Lindon JC \& Holmes E (1999) 'Metabonomics': understanding the metabolic responses of living systems to pathophysiological stimuli via multivariate statistical analysis of biological NMR spectroscopic data. Xenobiotica 29, 1181-1189.

11. Rerat AA, Vaissade P \& Vaugelade P (1984) Absorption kinetics of some carbohydrates in conscious pigs .2. Quantitative aspects. BrJ Nutr 51, 517-529.

12. Bach Knudsen KE, Laerke HN, Steenfeldt S, et al. (2006) In vivo methods to study the digestion of starch in pigs and poultry. Anim Feed Sci Technol 130, 114-135.

13. Bock JL (1982) Analysis of serum by high-field proton nuclear magnetic-resonance. Clin Chem 28, 1873-1877.

14. Salek RM, Xia J, Innes A, et al. (2010) A metabolomic study of the CRND8 transgenic mouse model of Alzheimer's disease. Neurochem Int 56, 937-947.

15. Nicholson JK, Buckingham MJ \& Sadler PJ (1983) Highresolution H-1-NMR studies of vertebrate blood and plasma. Biochem J 211, 605-615.

16. Nicholson JK, Connelly J, Lindon JC, et al. (2002) Metabonomics: a platform for studying drug toxicity and gene function. Nat Rev Drug Discov 1, 153-161.

17. Bertram HC, Bach Knudsen KE, Serena A, et al. (2006) NMR-based metabonomic studies reveal changes in the biochemical profile of plasma and urine from pigs fed high-fibre rye bread. BrJ Nutr 95, 955-962.

18. Bertram HC, Hoppe C, Petersen BO, et al. (2007) An NMRbased metabonomic investigation on effects of milk and meat protein diets given to 8 -year-old boys. Br J Nutr $\mathbf{9 7}$, $758-763$. 
19. Bertram HC, Malmendal A, Nielsen NC, et al. (2009) NMRbased metabonomics reveals that plasma betaine increases upon intake of high-fiber rye buns in hypercholesterolemic pigs. Mol Nutr Food Res 53, 1055-1062.

20. Fardet A, Canlet C, Gottardi G, et al. (2007) Whole-grain and refined wheat flours show distinct metabolic profiles in rats as assessed by a H-1 NMR-based metabonomic approach. J Nutr 137, 923-929.

21. Solanky KS, Bailey NJ, Beckwith-Hall BM, et al. (2005) Biofluid H-1 NMR-based metabonomic techniques in nutrition research metabolic effects of dietary isoflavones in humans. J Nutr Biochem 16, 236-244.

22. Solanky KS, Bailey NJC, Holmes E, et al. (2003) NMR-based metabonomic studies on the biochemical effects of epicatechin in the rat. J Agri Food Chem 51, 4139-4145.

23. Serena A, Jorgensen H \& Bach Knudsen KE (2007) The absorption of lactic acid is more synchronized with the absorption of glucose than with the absorption of shortchain fatty acids - a study with sows fed diets varying in dietary fibre. Liv Sci 109, 118-121.

24. Serena A, Jorgensen H \& Bach Knudsen KE (2009) Absorption of carbohydrate-derived nutrients in sows as influenced by types and contents of dietary fiber. J Anim Sci 87, 136-147.

25. Yde CC, Bertram HC \& Bach Knudsen KE (2010) NMR-based metabonomics reveals distinct metabolic profiles of plasma from sows after consumption of diets with contrasting dietary fibre levels and composition. Liv Sci 133, 26-29.

26. Serena A, Jorgensen H \& Bach Knudsen KE (2008) Digestion of carbohydrates and utilization of energy in sows fed diets with contrasting levels and physicochemical properties of dietary fiber. J Anim Sci 86, 2208-2216.

27. Meiboom S \& Gill D (1958) Modified spin-echo method for measuring nuclear relaxation times. Rev Sci Instrum 29, 688-691.

28. van Velzen EJJ, Westerhuis JA, van Duynhoven JPM, et al. (2008) Multilevel data analysis of a crossover designed human nutritional intervention study. J Proteome Res 7, 4483-4491.

29. van Velzen EJJ, Westerhuis JA, van Duynhoven JPM, et al. (2009) Phenotyping tea consumers by nutrikinetic analysis of polyphenolic end-metabolites. I Proteome Res $\mathbf{8}$, $3317-3330$
30. Westerhuis JA, Hoefsloot HCJ, Smit S, et al. (2008) Assessment of PLSDA cross validation. Metabolomics 4, 81-89.

31. Anderssen E, Dyrstad K, Westad F, et al. (2006) Reducing over-optimism in variable selection by cross-model validation. Chemometr Intell Lab Syst 84, 69-74.

32. Smit S, van Breemen MJ, Hoefsloot HCJ, et al. (2007) Assessing the statistical validity of proteomics based biomarkers. Anal Chim Acta 592, 210-217.

33. Breitling R, Armengaud P, Amtmann A, et al. (2004) Rank products: a simple, yet powerful, new method to detect differentially regulated genes in replicated microarray experiments. FEBS Lett 573, 83-92.

34. Martens HA \& Dardenne P (1998) Validation and verification of regression in small data sets. Chemometr Intell Lab Syst 44, 99-121.

35. Littell RC, Milliken GA, Storup, et al. (1996) SAS (R) System for Mixed Models. Cary, NC: SAS Institute, Inc.

36. Finkelstein JD \& Martin JJ (1984) Methionine metabolism in mammals - distribution of homocysteine between competing pathways. $J$ Biol Chem 259, 9508-9513.

37. Olthof MR \& Verhoef P (2005) Effects of betaine intake on plasma homocysteine concentrations and consequences for health. Curr Drug Metab 6, 15-22.

38. Sakamoto A, Nishimura Y, Ono H, et al. (2002) Betaine and homocysteine concentrations in foods. Pediatr Int $\mathbf{4 4}$, 409-413.

39. Wyss M \& Kaddurah-Daouk R (2000) Creatine and creatinine metabolism. Physiol Rev 80, 1107-1213.

40. Brosnan JT, Wijekoon EP, Warford-Woolgar L, et al. (2009) Creatine synthesis is a major metabolic process in neonatal piglets and has important implications for amino acid metabolism and methyl balance. J Nutr 139, 1292-1297.

41. Hoffman JR, Ratamess NA, Kang J, et al. (2009) Effect of betaine supplementation on power performance and fatigue. J Int Soc Sports Nutr 6 (epublication 27 February 2009).

42. Liu ML, Nicholson JK \& London JC (1996) High-resolution diffusion and relaxation edited one- and two-dimensional H-1 NMR spectroscopy of biological fluids. Anal Chem $\mathbf{6 8}$, 3370-3376.

43. Tiziani S, Einwas AH, Lodi A, et al. (2008) Optimized metabolite extraction from blood serum for $\mathrm{H}-1$ nuclear magnetic resonance spectroscopy. Anal Biochem 377, 16-23. 